\title{
Fitness, physical activity, and academic achievement in overweight/obese children
}

Running heading: Fitness, activity, and academic achievement

Cristina Cadenas-Sanchez ${ }^{1}$, Jairo H. Migueles ${ }^{1}$, Irene Esteban-Cornejo ${ }^{2,1}$, Jose Mora-

Gonzalez $^{1}$, Pontus Henriksson ${ }^{3,4}$, María Rodriguez-Ayllon ${ }^{1}$, Pablo Molina-García ${ }^{1}$,

Marie Löf ${ }^{3,4}$, Idoia Labayen ${ }^{5}$, Charles H. Hillman ${ }^{2,6}$, Andrés Catena ${ }^{7}$, Francisco B.

Ortega $^{1,3}$

${ }^{1}$ PROFITH "PROmoting FITness and Health through physical activity" research group, Department of Physical and Sports Education, Faculty of Sport Sciences, University of Granada, Granada, Spain

${ }^{2}$ Center for Cognitive and Brain Health, Department of Psychology, Northeastern University, Boston, Massachusetts, USA.

${ }^{3}$ Department of Biosciences and Nutrition at NOVUM, Karolinska Institutet, Huddinge, Sweden.

4 Department of Medical and Health Sciences, Linköping University, Linköping, Sweden.

${ }^{5}$ Department of Health Sciences, Public University of Navarra, Pamplona, Spain

${ }^{6}$ Department of Physical Therapy, Movement, \& Rehabilitation Sciences, Northeastern University, Boston, Massachusetts, USA

${ }^{7}$ Department of Experimental Psychology, Mind, Brain and Behavior Research Center (CIMCYC), University of Granada, Granada, Spain

\section{Corresponding author:}


Cristina Cadenas-Sánchez, Department of Physical and Sports Education, Faculty of

Sport Sciences, University of Granada, Carretera de Alfacar s/n, Granada 18071, Spain.

Tel. +34 958 244353. Fax. +34958249428

E-mail: cadenas@ugr.es

ORCID: 0000-0002-4513-9108

Word count: 4000

\section{Authors' contact details}

Cristina Cadenas-Sanchez, cadenas@ugr.es

Jairo H Migueles, jairohm@ugr.es

Irene Esteban-Cornejo, ireneesteban@ugr.es

Jose Mora-Gonzalez, jmorag@ugr.es

Pontus Henriksson, pontus.henriksson@,ki.se

Maria Rodriguez-Ayllon, rodriguezm@ugr.es

Pablo Molina-Garcia,pablomolinag5@gmail.com

Marie Löf, marie.lof@ki.se

Idoia Labayen, idoia.labayen@unavarra.es

Charles H Hillman, c.hillman@northeastern.edu

Andrés Catena, acatena@ugr.es

Francisco B Ortega, ortegaf@ugr.es 


\begin{abstract}
The aim of this study was to examine the associations of fitness and physical activity with academic achievement in children with overweight/obesity. A total of 106 (10.0 \pm 1.1 years, 61 boys) children participated. The fitness components were assessed by field and laboratory-based tests. Physical activity was measured via accelerometry. The academic achievement was assessed by a standardized test and school-grades. Field-based cardiorespiratory fitness was associated with language skills ( $ß-$ standardized- ranging from 0.281 to $0.365, \mathrm{p}<0.01$ ). The field-based muscular strength was associated with grade point average, natural and social sciences, and foreign language $(\beta=0.280-0.326$, all $\mathrm{p} \leq 0.01)$. Speed-agility was associated with some language-related skills $(~(=0.325-0.393$, all $\mathrm{p} \leq 0.01)$. The laboratory-based muscular strength also showed an association with mathematics skills $(\beta=0.251-0.306$, all $\mathrm{p} \leq 0.01)$. Physical activity did not show significant association with academic achievement ( $p>0.01)$. Overall, the significant associations observed for muscular strength and speed/agility were attenuated and disappeared in many cases after additional adjustments for body mass index and cardiorespiratory fitness, indicating that these associations are inter-dependent. Our study contributes to previous findings by indicating that other fitness components apart from cardiorespiratory fitness, such as muscular strength and speed-agility, are positively associated with academic achievement. However, these associations appear to be dependent on body mass index and cardiorespiratory fitness.
\end{abstract}

Keywords: Aerobic fitness. Academic performance. Light physical activity. Moderate physical activity. Vigorous physical activity. Moderate-to-vigorous physical activity. 


\section{Introduction}

In childhood, cognition is an important predictor of physical and mental health across the lifespan (Diamond, 2013). Academic achievement is one way of measuring cognition in children, and interest in this outcome has grown rapidly in recent years due to its relevance to the school settings and educational policies (Donnelly et al., 2016). Schools have received mounting pressure to increase the time devoted to core subjects (e.g., language, math, and science), and, consequently, a decreased time has been allotted to other subjects such as physical education, arts, and music. However, a recent position stand from the American College of Sports Medicine (Donnelly et al., 2016) suggests that this strategy is ill-suited, since health-related factors, such as physical fitness (hereafter referred to as fitness) and physical activity, are positively associated with cognitive health and academic achievement.

Fitness is considered a powerful marker of health in children and adolescents (Ortega, Ruiz, Castillo, \& Sjostrom, 2008). The main health-related components are cardiorespiratory, muscular strength, and speed-agility fitness (Ortega et al., 2008). Previous studies have mainly examined the relationship of cardiorespiratory fitness with academic outcomes, concluding that a higher fitness level is associated with higher academic achievement in children (Aadland, Moe, et al., 2017; Donnelly et al., 2016; Esteban-Cornejo, Tejero-Gonzalez, Martinez-Gomez, del-Campo, et al., 2014; TorrijosNino et al., 2014). However, far less investigated are the associations of muscular and speed-agility fitness with academic achievement (Donnelly et al., 2016). In this regard, Kao et al. (Kao, Westfall, Parks, Pontifex, \& Hillman, 2017) highlighted the importance of research focusing on muscular fitness and its association with cognitive health. Consonant with this assumption, our group recently examined the role of speed-agility 
fitness on brain structure, concluding that this might be another component of fitness (along with cardiorespiratory fitness) with a strong potential to improve brain development and with implications for better academic performance in children with overweight/obesity (Esteban-Cornejo et al., 2017). Thus, a greater understanding of the relationship between muscular and speed-agility fitness with academic achievement is needed.

Physical activity, an independent but strongly related construct to fitness, is associated with a wide-range of benefits for children's physical and mental health (Janssen \& Leblanc, 2010). Therefore, the time spent in different physical activities (i.e. light, moderate, vigorous, and moderate-to-vigorous physical activity -MVPA-) may also be associated with academic achievement. Previous systematic reviews and meta-analyses have shown a positive influence of physical activity on academic performance (AlvarezBueno et al., 2016; Donnelly et al., 2016), with MVPA being the most studied intensity in this relationship. However, such a conclusion remains controversial, given that a number of reports appear in the literature demonstrating positive (Dwyer, Sallis, Blizzard, Lazarus, \& Dean, 2001; Syvaoja et al., 2013), negative (Esteban-Cornejo, Tejero-Gonzalez, Martinez-Gomez, Cabanas-Sanchez, et al., 2014), and non-significant results (Aadland, Moe, et al., 2017; Hansen, Herrmann, Lambourne, Lee, \& Donnelly, 2014; LeBlanc et al., 2012; Pindus et al., 2016; Syvaoja et al., 2013) between physical activity and academic outcomes.

In addition, previous studies examining fitness and physical activity in relation to academic achievement have mainly focused on healthy-weight children, while there is a lack of information on children with overweight/obesity (for exceptions see Davis et al. (Davis \& Cooper, 2011)). Therefore, the aim of this study was to examine the 
associations of the different components of fitness (cardiorespiratory, muscular, and speed-agility) as well as physical activity with academic achievement in children with overweight/obesity. Further exploratory analyses will describe the interactive role of body mass index (BMI) and fitness in these associations. We hypothesized that higher fitness levels, regardless of the component, would be associated with better academic achievement. We believed that after additional adjustments of BMI and cardiorespiratory fitness, the associations with other fitness components (muscle strength, speed-agility) would be attenuated or would disappear. Based on prior studies (Hansen et al., 2014; LeBlanc et al., 2012; Pindus et al., 2016; Syvaoja et al., 2013), we further hypothesized that physical activity would not be related to academic achievement outcomes. The public health implications resulting from our hypothesis highlight the relevance of developing not only cardiorespiratory fitness but also muscular strength and speed-agility fitness to improve academic achievement in overweight/obese children.

\section{Material and methods}

Design and participants

This study is under the framework the ActiveBrains Project

(http://profith.ugr.es/activebrains), a randomized controlled trial that aims to investigate the effect of a 20 -week physical activity intervention on brain structure and function, cognition, academic achievement, and physical and mental health outcomes in children with overweight/obesity (Cadenas-Sanchez, Mora-Gonzalez, et al., 2016). This manuscript utilizes the baseline data collected prior to randomization. Children were recruited in the Endocrinology Unit of San Cecilio and Materno Infantil Hospitals from Granada (Spain). Additional strategies including contacting with the head teacher of 
schools, radio and television were applied. Further information on recruitment (inclusion and exclusion criteria, etc.) can be found elsewhere (Cadenas-Sanchez, MoraGonzalez, et al., 2016).

Out of 115 initially assessed for eligibility, a total of 110 children with overweight/obesity (categorization based on the World Obesity Federation cut-off points (Bervoets \& Massa, 2014; Cole \& Lobstein, 2012)) aged 8-11 years old accepted to participate in our project (response rate: $95.7 \%)$. From this sample, $106(10.0 \pm 1.1$ years old, 61 boys) had valid data for fitness, physical activity, and academic achievement outcomes, and were included in the analyses. We informed their parents or legal guardians about the aims of the project, who signed the informed consent to participate in the study. The ActiveBrains Project was approved by the Review Committee for Research Involving Human Subjects at the University of Granada, and it was registered as a clinical trial (NCT02295072, https://clinicaltrials.gov).

\section{Measures}

\section{Anthropometric characteristics}

The weight $(\mathrm{kg})$ and height $(\mathrm{cm})$ were measured without shoes and in light clothing (underwear). All measures were taken twice (not consecutively) by the same trained evaluator, and an average of the two values was used. The BMI was calculated as weight $/$ height $^{2}\left(\mathrm{~kg} / \mathrm{m}^{2}\right)$.

\section{Sociodemographic characteristics}

The parental educational level was self-reported via collection of their maximum educational level achieved (none, primary, secondary, and university). We then 
categorized their responses into low (none or primary), medium (secondary), and high (university) educational level.

Fitness: Field- and Laboratory-based tests

\section{Field-based fitness}

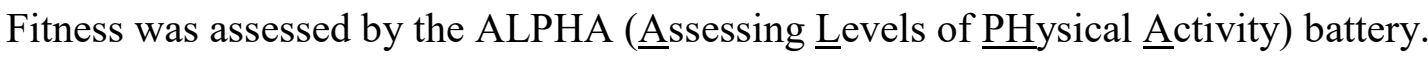
Collectively, these fitness tests have been shown to be feasible, reliable, and valid for this age group (Artero et al., 2011; Castro-Pinero et al., 2010; Ruiz et al., 2009). Briefly, cardiorespiratory fitness was assessed by a $20 \mathrm{~m}$ shuttle-run test, which consisted in running back and forth between two lines (20m apart) following an audio signal. The test started at $8.5 \mathrm{~km} / \mathrm{h}$, and the speed progressively increased $0.5 \mathrm{~km} / \mathrm{h}$ per minute. The test finished when the participant stopped because of exhaustion or when they did not reach the end lines concurrent with the audio signal on two consecutive laps. The number of completed laps was recorded for the analyses.

The muscular strength was assessed by the handgrip strength and standing long jump tests. The handgrip strength test measures the maximal strength of the upper-limb using a digital dynamometer (TKK 5401, Grip-D, Takei, Tokyo, Japan) (Cadenas-Sanchez, Sanchez-delgado, et al., 2016). The children squeezed the dynamometer as much as possible for 2-3 seconds. Each hand was measured twice, and the best result of each hand was retained and averaged for the analyses. The standing long jump test assesses the explosive strength of the lower-limbs. This test required the participant to jump as far as possible, remaining upright. We recorded the distance jumped from the take-off line to the nearest point of contact on the landing (back of the heel). This test was performed three times, and the best result was used for the analyses. 
Speed-agility fitness was assessed by the $4 \times 10 \mathrm{~m}$ shuttle-run test. This test consisted in running and changing direction as fast as possible between 2 lines (10 $\mathrm{m}$ apart). The children had to exchange sponges at each line (4 times x 10 meters). For this test, the fastest completion time was recorded in seconds (sec). This test was performed twice, and the best result (the lowest completion time) was used. For analysis purposes, we inverted this variable by multiplying the test completion time (sec) by -1 . Thus, higher scores indicated better performance.

\section{Laboratory-based fitness}

In addition, we assessed cardiorespiratory and muscular strength fitness in laboratory conditions. Cardiorespiratory fitness was assessed by a maximal incremental treadmill test recommended by the American College of Sports Medicine for poorly fit children. The test consisted in walking on a treadmill at a constant speed $(4.8 \mathrm{~km} / \mathrm{h})$ starting at a $6 \%$ slope with grade increments of $1 \%$ per minute until volitional exhaustion. The criteria for reaching maximal oxygen uptake were (1) volitional fatigue ( $>8$ points in the OMNI scale), (2) a plateau in $\mathrm{VO}_{2}$ max during the last two stages of the exercise $(<2.0$ $\mathrm{mL} \cdot \mathrm{kg}-1 \cdot \mathrm{min}-1)$, achieved at $>85 \%$ of age-predicted maximum heart rate, and/or (3) a respiratory exchange ratio of $\geq 1.0$.

The muscular strength was assessed by one-repetition-maximum (1-RM) exercises. The children performed both bench press and leg press tests to evaluate the upper- and lower-limb muscular strength, respectively. A familiarization phase was performed with the aim to ensure that children knew the technique and could perform the exercise correctly (i.e. control movement and proper breathing). The protocol for the 1-RM tests in children has been published previously (Faigenbaum, Milliken, \& Westcott, 2003). All tests were performed once and on different days. 


\section{Physical activity}

Physical activity was assessed by accelerometers (GT3X+, ActiGraph, Pensacola, FL, USA) placed on the non-dominant wrist and right hip during 7 consecutive days (24h). The participants were instructed to remove the accelerometers only for water activities (i.e., bathing or swimming). The raw accelerations collected at a sampling frequency of $100 \mathrm{~Hz}$ were processed to derive the Euclidean norm minus one $\mathrm{g}$ (ENMO) metric in $\mathrm{R}$ (v. 3.1.2, https://www.cran.r-project.org/) using the GGIR package (v. 1.5-12, https://cran.r-project.org/web/packages/GGIR/) (van Hees et al., 2013). ActiGraph's activity counts over $5 \mathrm{~s}$ epochs were imported. The inclusion criteria to be included in the analyses were $\geq 600 \mathrm{~min} /$ day of waking hours and $\geq 240 \mathrm{~min} /$ day of sleeping hours for a valid day, and a minimum of 4 days (3 weekdays and 1 weekend day). Detailed information about the data processing is shown in Supplemental Digital Content 1. Physical activity (i.e. light, moderate, vigorous, and MVPA) was classified based on the Hildebrand et al. (Hildebrand, Hansen, van Hees, \& Ekelund, 2016; Hildebrand, VT, Hansen, \& Ekelund, 2014) cut-off points. To thoroughly investigate the independent associations of MVPA with academic achievement, we also identified bout durations lasting at least 1,5 , and 10 minutes with a drop tolerance of $20 \%$ of the time.

Academic achievement: Woodcock-Muñoz standardized test and school grades

\section{Woodcock-Muñoz standardized test}

The Woodcock-Muñoz test battery is a standardized academic achievement test, which measures components of language, mathematics, and science. This battery is divided into two parts: standard and extended tests. In our study, we used the standard tests, which contain three reading tests, two oral language tests, three written language tests, 
and three mathematics tests. In addition, since science is considered a core academic subject in school, we evaluated one test of the extended battery, which was based on biological sciences, social sciences, and humanities. All tests were performed individually by a trained evaluator, and the testing time ranged from 100 to $120 \mathrm{~min}$. The data registered for each child was individually checked by two trained evaluators. All data were recorded in the Compuscore and Profile software version 3.1 (Riverside Publishing Company, Itasca, IL, USA) and grouped into components (i.e. total achievement, reading, oral language, writing, written expression, mathematics, calculation skills, and science). Detailed information about the interpretation of each of these components is provided in Supplemental Digital Content 2, Table S1. The standard score was selected for these analyses.

\section{School grades}

As a second indicator of academic achievement, the school grades were collected from the official school records of $80 \%$ of the study sample $(n=83)$. Since the school records were provided qualitatively (i.e. insufficient, sufficient, good, very good, outstanding), we registered the grades based on a scale from 1 to 5 . The mean grade per subject of the previous academic course was used for the analyses. The grade-point average, language, mathematics, natural and social sciences, and foreign language (i.e. English) were recorded.

\section{Statistical analyses}

The demographic information of the study sample was tested using the independentsamples t-test (for continuous variables) and Chi-square test (for categorical variables) to examine differences between sexes. We also examined sex-interactions with fitness 
and physical activity in relation to academic achievement, and we observed no evidence $(p>0.1)$. Confounders were selected after examining their influence on the academic achievement estimates. The influence of the paternal education was lower and not significant compared to the maternal educational level. Thus, the maternal education was included as covariate.

To test the relationship between predictors and outcomes, linear regression analyses (presented as standardized beta, $\beta$ ) were performed adjusting for age, sex, and maternal education (Model 1). Moreover, to test the role of BMI and fitness, we additionally adjusted for BMI and cardiorespiratory fitness (or speed-agility when the cardiorespiratory fitness was the independent variable) (Model 2).

Associations between predictors were checked by bivariate correlations (Supplemental Digital Content 3, Table S2). Likewise, multicollinearity analyses were also conducted between independent variables, showing the highest variance inflation factor of 2.68. Therefore, no multicollinearity was observed.

We presented physical activity estimates based on those obtained from the wrist-worn accelerometer and calculated with the ENMO metric (Hildebrand et al., 2014). Nevertheless, given that different placement and processing criteria result in different estimations of physical activity (Kerr et al., 2017; Migueles et al., 2017), we also examined whether the methods used for physical activity estimations, i.e. ENMO for hip and activity counts for hip and wrist, change the results in its association with academic achievement. This was done since none of the methods have thus far demonstrated to outperform the rest. Thus, until a harmonization is reached, it is highly relevant to evaluate whether investigated associations between accelerometer variables 
and investigated outcomes differ when using different placement and processing criteria (Kerr et al., 2017).

All the analyses were performed using SPSS Statistics version 20 (IBM Corporation, NY, USA), and the level of significance was set at $p<0.05$.

\section{Results}

Demographic characteristics

The demographic characteristics of the study sample are shown in Table 1. Briefly, the weight status analysis showed that $24.5 \%$ of the study sample was overweight, $44.3 \%$ was categorized as obesity type $1,19.8 \%$ presented obesity type 2 , and the remaining $11.3 \%$ was grouped as obesity type 3 . Boys showed greater fitness performance in all field and laboratory tests compared to girls (all $\mathrm{p}>0.01$ ), except for lower-limb muscular strength (i.e.1-RM bench press) $(\mathrm{p}=0.45)$. Objective physical activity outcomes were also higher in boys compared to girls (all $p \leq 0.01$ ), with the exception of light physical activity, which did not differ between sexes. Academic achievement characteristics did not show differences between sexes (all $\mathrm{p} \geq 0.1$, Table 2 ).

\section{Fitness and academic achievement}

The linear regression analyses between fitness and academic achievement measured by the Woodcock-Muñoz standardized test and school grades are shown in Table $\mathbf{3}$.

Briefly, after adjusted for age, sex and maternal education (Model 1), in field tests, cardiorespiratory fitness (i.e. the $20 \mathrm{~m}$ shuttle-run test) was associated with writing skills measured by Woodcock-Muñoz (all $\beta \geq 0.281$, all $p<0.01$ ); the upper-limbs muscular strength (i.e. handgrip strength) was associated with school grades including the grade point average, natural and social sciences, and foreign language (all $\beta \geq 0.272$, all 
$\mathrm{p} \leq 0.01$ ); speed-agility fitness (i.e. $4 \times 10 \mathrm{~m}$ shuttle-run test) was associated with writing skills measured by Woodcock-Muñoz (all $\beta \geq 0.325$, all $p<0.01$ ). The laboratory fitness tests only showed significant associations between the lower-limbs muscular strength (i.e.1-RM leg press) and mathematics skills measured by Woodcock-Muñoz (all $\beta \geq 0.251$, all $p<0.01$ ). No strong associations ( $p<0.01)$ were found for the remaining fitness components (Table 3).

After additional adjustment of BMI and cardiorespiratory fitness or speed-agility (Model 2), the results observed for the field and laboratory tests were attenuated, and significant associations disappeared except for those in the lower-limbs muscular strength (1-RM leg press) (Table 3). Models 2 did not present multicollinearity between physical fitness variables (all variance inflation factors $<3$, bivariate correlations across fitness components can be found in Table S2).

\section{Physical activity and academic achievement}

The linear regression analyses between physical activity and academic achievement using the Woodcock-Muñoz test and school grades are shown in Table 4. Overall, the results showed that physical activity was not significantly associated with academic achievement in any of the models examined. In sensitivity analyses, we examined the relationships between physical activity obtained from different accelerometer metrics (i.e., ENMO and activity counts) and placements (i.e., right hip and non-dominant wrist), and the findings were consistent overall, showing no association (data not shown).

\section{Discussion}


The current findings indicate that the various components of health-related fitness were positively associated with academic achievement, measured by both standardized achievement tests and school grades. Specifically, higher levels of cardiorespiratory fitness, muscular strength, and speed-agility were related to higher academic achievement in children with overweight/obesity. However, all significant associations found were attenuated or disappeared after additional adjustments for BMI and other fitness components, suggesting that they are inter-dependent in their association with academic achievement. On the other hand, physical activity did not demonstrate an association with any of the academic outcomes studied, suggesting a differential relationship between these health factors (i.e., fitness and physical activity).

\section{Fitness and academic achievement}

Our findings are in accordance with previous reports that showed positive associations between fitness and academic achievement in similarly aged children (Aadland, Moe, et al., 2017; Esteban-Cornejo, Tejero-Gonzalez, Martinez-Gomez, del-Campo, et al., 2014; Torrijos-Nino et al., 2014). In our study, a field measure of cardiorespiratory fitness was associated with language-related skills (i.e. writing and written expression). This result is in line with that of Telford et al. (Telford, Cunningham, Telford, \& Abhayaratna, 2012), who observed a positive relationship between the $20 \mathrm{~m}$ shuttle-run test and writing in children aged 8.5-10.5. In accordance with this result, growing evidence depicts the role of cardiorespiratory fitness on brain and cognition in children during preadolescent development (Esteban-Cornejo et al., 2017; Hillman et al., 2014; Ortega et al., 2017). However, the mechanisms for this association remain unclear. It has been suggested that aerobic activity influences growth factors, including brain-derived neurotrophic factor (BDNF), insulin-like growth factor (IGF1), and vascular endothelial 
growth factor (VEGF), which are involved in neurogenesis, angiogenesis, cellular proliferation, and neural plasticity processes that result in healthier brains (Cotman, Berchtold, \& Christie, 2007). Likewise, a greater level of fitness has positive effects on molecular and cellular aspects of brain structure and function, particularly in specific regions and networks (e.g., prefrontal cortex and associated executive control network [basal ganglia], hippocampus, etc.) that underlie specific cognitive functions (e.g., mathematics, language, etc.) (Chaddock, Erickson, Prakash, Kim, et al., 2010; Chaddock, Erickson, Prakash, VanPatter, et al., 2010). These changes might be related to improvements on brain, cognition and academic achievement.

In contrast with our results, other studies have observed that cardiorespiratory fitness (measured via both field and laboratory tests) was related to higher reading skills (as a measure of language) (Davis \& Cooper, 2011; Rauner, Walters, Avery, \& Wanser, 2013) and mathematics/numeracy (Aadland, Moe, et al., 2017; Davis \& Cooper, 2011). In particular, the only study which analyzed fitness and academic achievement in overweight children is not in agreement with our findings, since they found a positive association for reading and mathematics, whilst we did not (Davis \& Cooper, 2011). Such discrepancies among results could be explained by the characteristics of the study sample (Davis et al.: overweight vs. this study: overweight and obese) and the different confounders used (Davis et al.: race, sex, primary caregiver's education level vs. this study: sex, age, maternal education). Moreover, we found differences in the results of our study between measures of cardiorespiratory fitness (i.e. field-based and laboratory tests), which could be explained by: 1) the nature of the measurements, being one more focused on performance measurement (greater number of laps, higher performance) and the other on a physiological marker $\left(\mathrm{VO}_{2} \mathrm{max}\right)$. As an example of the different nature of 
these two variables, laps increase with age whilst $\mathrm{VO}_{2}$ max may decreases with age from childhood to adolescence in girls but not in boys (Aadland et al., 2019; Tomkinson et al., 2016); 2) the natural condition of running in a field-based test (running in a playground, with general fatigue as a reason to terminate the maximum test, etc.) versus the non-natural conditions of the laboratory test (e.g. wearing a mask, walking on a treadmill at a steep slope, with higher local muscular fatigue as a reason to terminate the maximum test, etc.); and 3) the higher maximum heart rate observed during the field test compared to the laboratory test (mean differences: +4.2 beats per minute, $\mathrm{p}<0.01$ ).

In regard to muscular strength, our findings in the field and laboratory tests showed significant associations with mathematics skills in Woodcock-Muñoz and school grades (grade point average, natural and social sciences, and foreign language). The relationship observed for the muscular strength and mathematics scores is consonant with evidence from previous cross-sectional findings in children (Eveland-Sayers, Farley, Fuller, Morgan, \& Caputo, 2009). However, other studies have also reported a lack of significant findings between muscular strength and these academic components (Esteban-Cornejo, Tejero-Gonzalez, Martinez-Gomez, del-Campo, et al., 2014; Kao et al., 2017). The discrepancies between findings could be due to the different characteristics of the study sample, fitness, and academic measurements used as well as the covariates applied in the model. Although continued work is necessary to expose the exact mechanisms relating muscular strength and cognitive and academic performance in children, previous studies in the elderly have shown the role of resistance training on these outcomes (Cassilhas et al., 2007). For instance, after a 6-month trial, those participants involved in the resistance training program demonstrated benefits in memory performance and verbal concept formation (Cassilhas et al., 2007). These 
findings raise the possibility that a broader spectrum of cognitive functions could also show improvement with resistance training. To the best of our knowledge, no study has examined science components individually and, therefore, it is difficult to compare our results with previous findings given the differences in content. Likewise, another explanation for differences between academic tests is that school grades are influenced by subjective teacher evaluations, making them a less objective outcome than standardized tests. Overall, although the relationship between muscular strength and academic achievement remains uncertain (Santana et al., 2017), our study supports the relevance of muscular strength during preadolescence.

Speed-agility fitness has been the least studied component in the literature. In fact, only two studies have examined this relationship using the $4 \times 10 \mathrm{~m}$ shuttle-run test and academic outcomes in normal weight children (Aadland, Moe, et al., 2017; EstebanCornejo, Tejero-Gonzalez, Martinez-Gomez, del-Campo, et al., 2014). Similar to our results for writing and written expression (language-related skills), Esteban-Cornejo et al. (Esteban-Cornejo, Tejero-Gonzalez, Martinez-Gomez, del-Campo, et al., 2014) found a significant association between speed-agility fitness and language. Likewise, Aadland et al. (Aadland, Moe, et al., 2017) found a positive relationship between motor skills (including speed-agility) and reading. The higher demands for coordination, agility, and memorization in the $4 \times 10 \mathrm{~m}$ shuttle-run test, which involves the temporal lobe (also crucial for memory and language) (Esteban-Cornejo et al., 2017), may be one potential explanation of these findings. Likewise, a recent study (Esteban-Cornejo et al., 2017) conducted by our group showed that those with higher speed-agility fitness presented higher gray matter volume in the inferior frontal gyrus and the superior 
temporal gyrus, which, in turn, were related to better academic performance (total academic achievement, reading, and academic fluency).

Our findings are of special importance, enhancing the role of fitness on the weight status condition. Previous literature showed that an excess of fat could be related with worse brain health (Han, Lawlor, \& Kimm, 2010). However, our findings extend the knowledge that this negative association could be attenuated or even reverted in those children presenting higher physical fitness levels as other authors observed recently (Garcia-Hermoso, Esteban-Cornejo, Olloquequi, \& Ramirez-Velez, 2017; MuntanerMas, Palou, Vidal-Conti, \& Esteban-Cornejo, 2018). Specifically, Muntaner-Mas et al. (Muntaner-Mas et al., 2018) concluded that cardiorespiratory fitness and speed-agility might attenuate the inverse relationship of obesity on academic achievement in children. Likewise, García-Hermoso et al. (Garcia-Hermoso et al., 2017) observed that also muscular strength may attenuate or even counteract the adverse influence of fatness on academic achievement. Therefore, the negative consequences of being overweight/obese on academic achievement could be diminished or even reversed by the effects of having higher levels of cardiorespiratory fitness, muscular strength or speed-agility on brain.

Moreover, to the best of our knowledge, this is the first study to analyze the unique relationship of cardiorespiratory, muscular strength, and speed-agility fitness. Our results shed light on the role of cardiorespiratory fitness as a confounder in the relationship between muscular strength, while speed-agility fitness also confounds cardiorespiratory fitness (i.e., confounding one another) on academic outcomes. Overall, our findings suggest that, after the additional adjustment of fitness, the unique relationship of cardiorespiratory fitness, muscular strength, and speed-agility with 
academic achievement was null or attenuated, indicating the role of fitness in driving the significant findings. However, further studies with larger samples are needed, and further examination of the effect of a physical exercise program on academic achievement in children with overweight/obesity should be conducted to corroborate the observed results.

\section{Physical activity and academic achievement}

Alternatively, we did not observe any association of objectively-measured physical activity with academic achievement, which is in agreement with most previous reports (Aadland, Moe, et al., 2017; Hansen et al., 2014; LeBlanc et al., 2012; Pindus et al., 2016; Syvaoja et al., 2013). However, it should be noted that examples in the literature do exist for both positive (Dwyer et al., 2001; Syvaoja et al., 2013) and negative (Esteban-Cornejo, Tejero-Gonzalez, Martinez-Gomez, Cabanas-Sanchez, et al., 2014) relationships between physical activity and academic outcomes. The explanation for the conflicting results may be the differences in the study sample, the method of measurement in collecting physical activity data (self-reported or accelerometry), the accelerometer data collection and processing criteria (cut-points, placement of the accelerometer, metric used, etc.), the control of confounding variables, and the academic achievement tests and outcomes studied (standardized versus school grades).

Considering the fitness and physical activity findings together, the differences observed in their association with academic outcomes in our study could be explained because fitness is considered a physiological condition or state, and thus, it shows less day-today variation than physical activity, which is a behavior with higher day-to-day variability (Aadland, Andersen, et al., 2017; Wickel \& Welk, 2010). As stated previously, physical activity is strongly related to fitness, being the main focus of the 
interventions intended to improve fitness. Thus, although a direct relationship has not been observed in the present study, future randomized controlled trials should focus on the inter-relationship between physical activity and fitness and how it affects academic achievement.

The main limitation of this study is its cross-sectional design, which cannot draw causality. However, these are the baseline data from an ongoing longitudinal study, and it is important to understand between-group differences that are observable prior to the intervention. The limited sample size, especially in the 1-RM or school grade outcomes, reduces the power of our analyses. Likewise, children from different schools may have been graded differently, being another limitation to consider. The strengths of this study are the inclusion of valid (Castro-Pinero et al., 2010), reliable (Artero et al., 2011), and health-related field and laboratory fitness tests (Ruiz et al., 2009); the novel analyses of physical activity based on different locations and metrics; and a comprehensive academic achievement battery measured via standardized tests and school grades.

Our study contributes to the literature by showing that other fitness components such as muscular and speed-agility fitness may contribute to better academic achievement performance, yet these associations are dependent on body mass index and cardiorespiratory fitness. No relationships were observed for physical activity and academic achievement. Accordingly, public health strategies should focus on improving multiple aspects of fitness as an effective approach to enhance academic achievement in children. Future randomized controlled trials are therefore needed in order to verify these results.

\section{Geolocation information}


Data from this study is from Granada (Spain)

\section{Acknowledgments}

The ActiveBrains project was funded by the Spanish Ministry of Economy and Competitiveness and the "Fondo Europeo de Desarrollo Regional (FEDER)" (DEP2013-47540). CC-S is supported by a grant from the Spanish Ministry of Economy and Competitiveness (BES-2014-068829). IE-C is supported by a grant from the Alicia Koplowitz Foundation. JHM and JM-G are supported by the Spanish Ministry of Education, Culture and Sport (FPU15/02645 and FPU14/06837, respectively). PH was supported by a grant from the Strategic Research Area Health Care Science, Karolinska Institutet/Umeå University. FBO is supported by a grant from the Spanish Ministry of Science and Innovation (RYC-2011-09011). Additional support was obtained from the University of Granada, Plan Propio de Investigación 2016, Excellence actions: Units of Excellence, Unit of Excellence on Exercise and Health (UCEES); by the Junta de Andalucia, Consejería de Conocimiento, Investigación y Universidades; the European Union's Horizon 2020 research and innovation programme under grant agreement No 667302; the SAMID III network, RETICS, funded by the PN I+D+I 2017-2021 (Spain), ISCIII- Sub-Directorate General for Research Assessment and Promotion, the European Regional Development Fund (ERDF) (Ref. RD16/0022) and the EXERNET Research Network on Exercise and Health in Special Populations (DEP2005-00046/ACTI). This work is part of a Ph.D. Thesis conducted in the Biomedicine Doctoral Studies of the University of Granada, Spain.

\section{Conflict of interest}

The authors declare that they have no conflict of interest. 


\section{References}

Aadland, E., Andersen, L. B., Skrede, T., Ekelund, U., Anderssen, S. A., \& Resaland, G. K. (2017). Reproducibility of objectively measured physical activity and sedentary time over two seasons in children; Comparing a day-by-day and a week-by-week approach. PLoS One, 12(12), e0189304.

Aadland, E., Anderssen, S. A., Andersen, L. B., Resaland, G. K., Kolle, E., \& SteeneJohannessen, J. (2019). Aerobic fitness thresholds to define poor cardiometabolic health in children and youth. Scandinavian Journal of Medicine and Science in Sports, 29(2), 240-250.

Aadland, Katrine Nyvoll, Moe, Vegard Fusche, Aadland, Eivind, Anderssen, Sigmund Alfred, Resaland, Geir Kåre, \& Ommundsen, Yngvar. (2017). Relationships between physical activity, sedentary time, aerobic fitness, motor skills and executive function and academic performance in children. Mental Health and Physical Activity, 12, 10-18.

Alvarez-Bueno, C., Pesce, C., Cavero-Redondo, I., Sanchez-Lopez, M., Pardo-Guijarro, M. J., \& Martinez-Vizcaino, V. (2016). Association of physical activity with cognition, metacognition and academic performance in children and adolescents: a protocol for systematic review and meta-analysis. BMJ Open, 6(6), e011065.

Artero, E. G., Espana-Romero, V., Castro-Pinero, J., Ortega, F. B., Suni, J., CastilloGarzon, M. J., \& Ruiz, J. R. (2011). Reliability of field-based fitness tests in youth. International Journal of Sports Medicine, 32(3), 159-169.

Bervoets, L., \& Massa, G. (2014). Defining morbid obesity in children based on BMI 40 at age 18 using the extended international (IOTF) cut-offs. Pediatric Obesity, 9(5), e94-98. 
Cadenas-Sanchez, C., Mora-Gonzalez, J., Migueles, J. H., Martin-Matillas, M., GomezVida, J., Escolano-Margarit, M. V., . . . Ortega, F. B. (2016). An exercise-based randomized controlled trial on brain, cognition, physical health and mental health in overweight/obese children (ActiveBrains project): Rationale, design and methods. Contemporary Clinical Trials, 47, 315-324.

Cadenas-Sanchez, C., Sanchez-delgado, G., Martinez-Tellez, B., Mora-González, J., Löf, M., Espana-Romero, V., . . Ortega, F. B. (2016). Reliability and validity of different models of hand-dynamometers. American Journal of Occupational Therapy, 70(4), 7004300010.

Cassilhas, R. C., Viana, V. A., Grassmann, V., Santos, R. T., Santos, R. F., Tufik, S., \& Mello, M. T. (2007). The impact of resistance exercise on the cognitive function of the elderly. Medicine and Science in Sports and Exercise, 39(8), 1401-1407.

Castro-Pinero, J., Artero, E. G., Espana-Romero, V., Ortega, F. B., Sjostrom, M., Suni, J., \& Ruiz, J. R. (2010). Criterion-related validity of field-based fitness tests in youth: a systematic review. British Journal of Sports Medicine, 44(13), 934-943.

Cole, T. J., \& Lobstein, T. (2012). Extended international (IOTF) body mass index cutoffs for thinness, overweight and obesity. Pediatric Obesity, 7(4), 284-294.

Cotman, C. W., Berchtold, N. C., \& Christie, L. A. (2007). Exercise builds brain health: key roles of growth factor cascades and inflammation. Trends in Neuroscience, 30(9), 464-472.

Chaddock, L., Erickson, K. I., Prakash, R. S., Kim, J. S., Voss, M. W., Vanpatter, M., . . . Kramer, A. F. (2010). A neuroimaging investigation of the association between aerobic fitness, hippocampal volume, and memory performance in preadolescent children. Brain Research, 1358, 172-183. 
Chaddock, L., Erickson, K. I., Prakash, R. S., VanPatter, M., Voss, M. W., Pontifex, M. B., ... Kramer, A. F. (2010). Basal ganglia volume is associated with aerobic fitness in preadolescent children. Developmental Neuroscience, 32(3), 249-256.

Davis, CatherineL, \& Cooper, S. (2011). Fitness, fatness, cognition, behavior, and academic achievement among overweight children: do cross-sectional associations correspond to exercise trial outcomes? Preventive Medicine, 52 Suppl 1, S65-69.

Diamond, A. (2013). Executive functions. Annual Review of Psychology, 64, 135-168. Donnelly, J. E., Hillman, C. H., Castelli, D., Etnier, J. L., Lee, S., Tomporowski, P., . . Szabo-Reed, A. N. (2016). Physical Activity, Fitness, Cognitive Function, and Academic Achievement in Children: A Systematic Review. Medicine and Science in Sports and Exercise, 48(6), 1197-1222.

Dwyer, Terence, Sallis, James F., Blizzard, Leigh, Lazarus, Ross, \& Dean, Kimberlie. (2001). Relation of Academic Performance to Physical Activity and Fitness in Children. Pediatric Exercise Science, 13(3), 225-237.

Esteban-Cornejo, I., Cadenas-Sanchez, C., Contreras-Rodriguez, O., Verdejo-Roman, J., Mora-Gonzalez, J., Migueles, J. H., . . Ortega, F. B. (2017). A whole brain volumetric approach in overweight/obese children: Examining the association with different physical fitness components and academic performance. The ActiveBrains project. Neuroimage, 159, 346-354.

Esteban-Cornejo, I., Tejero-Gonzalez, C. M., Martinez-Gomez, D., Cabanas-Sanchez, V., Fernandez-Santos, J. R., Conde-Caveda, J., . . Veiga, O. L. (2014). Objectively measured physical activity has a negative but weak association with academic performance in children and adolescents. Acta Paediatrica, 103(11), e501-506. 
Esteban-Cornejo, I., Tejero-Gonzalez, C. M., Martinez-Gomez, D., del-Campo, J., Gonzalez-Galo, A., Padilla-Moledo, C., . . . Veiga, O. L. (2014). Independent and combined influence of the components of physical fitness on academic performance in youth. Journal of Pediatrics, 165(2), 306-312 e302.

Eveland-Sayers, B. M., Farley, R. S., Fuller, D. K., Morgan, D. W., \& Caputo, J. L. (2009). Physical fitness and academic achievement in elementary school children. Journal of Physical Activity and Health, 6(1), 99-104.

Faigenbaum, A. D., Milliken, L. A., \& Westcott, W. L. (2003). Maximal strength testing in healthy children. Journal of Strength and Conditioning Research, 17(1), 162-166.

Garcia-Hermoso, A., Esteban-Cornejo, I., Olloquequi, J., \& Ramirez-Velez, R. (2017). Cardiorespiratory Fitness and Muscular Strength as Mediators of the Influence of Fatness on Academic Achievement. Journal of Pediatrics, 187, 127-133 e123.

Han, J. C., Lawlor, D. A., \& Kimm, S. Y. (2010). Childhood obesity. Lancet, 375(9727), 1737-1748.

Hansen, D. M., Herrmann, S. D., Lambourne, K., Lee, J., \& Donnelly, J. E. (2014). Linear/nonlinear relations of activity and fitness with children's academic achievement. Medicine and Science in Sports and Exercise, 46(12), 2279-2285.

Hildebrand, M., Hansen, B. H., van Hees, V. T., \& Ekelund, U. (2016). Evaluation of raw acceleration sedentary thresholds in children and adults. Scandinavian Journal of Medicine and Science in Sports, 27 (12):1814-1823.

Hildebrand, M., VT, V. A. N. Hees, Hansen, B. H., \& Ekelund, U. (2014). Age group comparability of raw accelerometer output from wrist- and hip-worn monitors. Medicine and Science in Sports and Exercise, 46(9), 1816-1824. 
Hillman, C. H., Pontifex, M. B., Castelli, D. M., Khan, N. A., Raine, L. B., Scudder, M. R., . . Kamijo, K. (2014). Effects of the FITKids randomized controlled trial on executive control and brain function. Pediatrics, 134(4), e1063-1071.

Janssen, I., \& Leblanc, A. G. (2010). Systematic review of the health benefits of physical activity and fitness in school-aged children and youth. The International Journal of Behavioral Nutrititon and Physical Activity, 7, 40.

Kao, S. C., Westfall, D. R., Parks, A. C., Pontifex, M. B., \& Hillman, C. H. (2017). Muscular and Aerobic Fitness, Working Memory, and Academic Achievement in Children. Medicine and Science in Sports and Exercise, 49(3), 500-508.

Kerr, J., Marinac, C. R., Ellis, K., Godbole, S., Hipp, A., Glanz, K., . . Berrigan, D. (2017). Comparison of Accelerometry Methods for Estimating Physical Activity. Medicine and Science in Sports and Exercise, 49(3), 617-624.

LeBlanc, M. M., Martin, C. K., Han, H., Newton, R., Jr., Sothern, M., Webber, L. S., . . . Williamson, D. A. (2012). Adiposity and physical activity are not related to academic achievement in school-aged children. Journal of Developmental and Behavioral Pediatrics, 33(6), 486-494.

Migueles, J. H., Cadenas-Sanchez, C., Ekelund, U., Delisle Nystrom, C., MoraGonzalez, J., Lof, M., . . . Ortega, F. B. (2017). Accelerometer Data Collection and Processing Criteria to Assess Physical Activity and Other Outcomes: A Systematic Review and Practical Considerations. Sports Medicine, 47(9), 18211845.

Muntaner-Mas, A., Palou, P., Vidal-Conti, J., \& Esteban-Cornejo, I. (2018). A Mediation Analysis on the Relationship of Physical Fitness Components, Obesity, and Academic Performance in Children. Journal of Pediatrics, 198, 9097 e94. 
Ortega, F. B., Campos, D., Cadenas-Sanchez, C., Altmae, S., Martinez-Zaldivar, C., Martin-Matillas, M., . . . Campoy, C. (2017). Physical fitness and shapes of subcortical brain structures in children. British Journal of Nutrition, 1-10.

Ortega, F. B., Ruiz, J. R., Castillo, M. J., \& Sjostrom, M. (2008). Physical fitness in childhood and adolescence: a powerful marker of health. International Journal of Obesity (Lond), 32(1), 1-11.

Pindus, D. M., Drollette, E. S., Scudder, M. R., Khan, N. A., Raine, L. B., Sherar, L. B., ... Hillman, C. H. (2016). Moderate-to-Vigorous Physical Activity, Indices of Cognitive Control, and Academic Achievement in Preadolescents. Journal of Pediatrics, 173, 136-142.

Rauner, R. R., Walters, R. W., Avery, M., \& Wanser, T. J. (2013). Evidence that aerobic fitness is more salient than weight status in predicting standardized math and reading outcomes in fourth- through eighth-grade students. Journal of Pediatrics, 163(2), 344-348.

Ruiz, J. R., Castro-Pinero, J., Artero, E. G., Ortega, F. B., Sjostrom, M., Suni, J., \& Castillo, M. J. (2009). Predictive validity of health-related fitness in youth: a systematic review. British Journal of Sports Medicine, 43(12), 909-923.

Santana, C. C. A., Azevedo, L. B., Cattuzzo, M. T., Hill, J. O., Andrade, L. P., \& Prado, W. L. (2017). Physical fitness and academic performance in youth: A systematic review. Scandinavian Journal of Medicine and Science in Sports, 27(6), 579603.

Syvaoja, H. J., Kantomaa, M. T., Ahonen, T., Hakonen, H., Kankaanpaa, A., \& Tammelin, T. H. (2013). Physical activity, sedentary behavior, and academic performance in Finnish children. Medicine and Science in Sports and Exercise, 45(11), 2098-2104. 
Telford, R. D., Cunningham, R. B., Telford, R. M., \& Abhayaratna, W. P. (2012). Schools with fitter children achieve better literacy and numeracy results: evidence of a school cultural effect. Pediatric Exercise Science, 24(1), 45-57.

Tomkinson, G. R., Lang, J. J., Tremblay, M. S., Dale, M., LeBlanc, A. G., Belanger, K., . . Leger, L. (2016). International normative $20 \mathrm{~m}$ shuttle run values from 1142 026 children and youth representing 50 countries. British Journal of Sports Medicine, 51 (21), 1545-1554.

Torrijos-Nino, C., Martinez-Vizcaino, V., Pardo-Guijarro, M. J., Garcia-Prieto, J. C., Arias-Palencia, N. M., \& Sanchez-Lopez, M. (2014). Physical fitness, obesity, and academic achievement in schoolchildren. Journal of Pediatrics, 165(1), 104109.

van Hees, V. T., Gorzelniak, L., Dean Leon, E. C., Eder, M., Pias, M., Taherian, S., . . . Brage, S. (2013). Separating movement and gravity components in an acceleration signal and implications for the assessment of human daily physical activity. PLoS One, 8(4), e61691.

Wickel, E. E., \& Welk, G. J. (2010). Applying generalizability theory to estimate habitual activity levels. Medicine \& Science in Sports \& Exercise, 42(8), 15281534. 
Table 1. Descriptive characteristics of the study sample.

\begin{tabular}{|c|c|c|c|c|}
\hline & All & Boys & Girls & $\mathrm{P}_{\mathrm{sex}}$ \\
\hline \multicolumn{5}{|c|}{ Anthropometric and sociodemographic characteristics (n=106; 61 boys): } \\
\hline Age (years) & $10.0 \pm 1.1$ & $10.1 \pm 1.1$ & $9.9 \pm 1.1$ & 0.473 \\
\hline Weight (kg) & $56.1 \pm 10.9$ & $56.5 \pm 10.5$ & $55.5 \pm 11.7$ & 0.624 \\
\hline Height (cm) & $144.2 \pm 8.3$ & $144.5 \pm 7.3$ & $143.7 \pm 9.6$ & 0.655 \\
\hline Body mass index $\left(\mathrm{kg} / \mathrm{m}^{2}\right)$ & $26.8 \pm 3.6$ & $26.9 \pm 3.7$ & $26.6 \pm 3.4$ & 0.634 \\
\hline \multicolumn{5}{|l|}{ Weight status $(n, \%) *$ : } \\
\hline Overweight & $26,24.5 \%$ & $15,24.6 \%$ & $11,24.4 \%$ & 0.721 \\
\hline Obesity type 1 & $47,44.3 \%$ & $28,45.9 \%$ & $19,42.2 \%$ & \\
\hline Obesity type 2 & $21,19.8 \%$ & $10,16.4 \%$ & $11,24.4 \%$ & \\
\hline Obesity type 3 & $12,11.3 \%$ & $8,13.1 \%$ & $4,8.9 \%$ & \\
\hline \multicolumn{5}{|l|}{ Maternal education ( $n, \%)$ : } \\
\hline Primary & $28,26.4 \%$ & $16,26.2 \%$ & $12,26.7 \%$ & 0.088 \\
\hline Secondary & $51,48.1 \%$ & $34,55.7 \%$ & $17,37.8 \%$ & \\
\hline University & $27,25.5 \%$ & $11,18.0 \%$ & $16,35.6 \%$ & \\
\hline \multicolumn{5}{|l|}{ Physical fitness: } \\
\hline \multicolumn{5}{|c|}{ Field-based test, physical fitness ( $n=106 ; 61$ boys): } \\
\hline 20m shuttle-run (laps) & $16.0 \pm 7.8$ & $17.0 \pm 8.2$ & $14.6 \pm 7.0$ & 0.127 \\
\hline Handgrip strength (kg) & $16.8 \pm 4.1$ & $17.2 \pm 3.8$ & $16.3 \pm 4.4$ & 0.284 \\
\hline Standing long jump $(\mathrm{cm})$ & $105.0 \pm 18.4$ & $106.3 \pm 17.4$ & $103.2 \pm 19.7$ & 0.406 \\
\hline 4x10m shuttle-run (sec) & $15.1 \pm 1.6$ & $14.9 \pm 1.7$ & $15.4 \pm 1.5$ & 0.128 \\
\hline \multicolumn{5}{|c|}{ Laboratory-based test, Cardiorespiratory fitness, $(n=104 ; 60$ boys): } \\
\hline $\begin{array}{l}\text { Treadmill test }\left(\mathrm{VO}_{2} \text { peak, }\right. \\
\mathrm{ml} / \mathrm{kg} / \mathrm{min})\end{array}$ & $36.9 \pm 5.0$ & $37.2 \pm 5.0$ & $36.4 \pm 5.1$ & 0.420 \\
\hline \multicolumn{5}{|c|}{ Laboratory-based test, Muscular strength, $(n=88 ; 55$ boys $)$ : } \\
\hline 1-RM bench press (kg) & $21.5 \pm 4.3$ & $22.4 \pm 4.4$ & $20.0 \pm 3.8$ & 0.009 \\
\hline 1-RM leg press (kg) & $135.4 \pm 26.3$ & $137.5 \pm 28.5$ & $133.1 \pm 22.5$ & 0.456 \\
\hline \multicolumn{5}{|c|}{ Physical activity (min/day; $n=100,58$ boys): } \\
\hline Light PA & $260.0 \pm 37.4$ & $254.2 \pm 62.3$ & $268.1 \pm 38.4$ & 0.068 \\
\hline Moderate PA & $44.3 \pm 16.4$ & $50.2 \pm 17.5$ & $36.2 \pm 10.2$ & $<0.001$ \\
\hline Vigorous PA & $7.03 \pm 4.3$ & $8.8 \pm 4.5$ & $4.7 \pm 2.4$ & $<0.001$ \\
\hline MVPA & $51.4 \pm 19.8$ & $58.9 \pm 21.0$ & $40.9 \pm 11.7$ & $<0.001$ \\
\hline 1-min bouts MVPA & $12.2 \pm 5.9$ & $14.8 \pm 5.7$ & $8.7 \pm 4.1$ & $<0.001$ \\
\hline 5-min bouts MVPA & $2.9 \pm 3.1$ & $4.0 \pm 3.4$ & $1.6 \pm 1.8$ & $<0.001$ \\
\hline 10-min bouts MVPA & $3.1 \pm 5.2$ & $4.5 \pm 6.1$ & $1.3 \pm 2.5$ & 0.002 \\
\hline
\end{tabular}

$\mathrm{VO}_{2} \mathrm{max}=$ maximum oxygen volume $\mathrm{VO}_{2}$ peak= peak oxygen volume. $\mathrm{RM}=$ Repetition maximum. $\mathrm{PA}=$ physical activity.

MVPA= moderate-to-vigorous physical activity. 
Data shown are mean \pm standard deviation or $\mathrm{n}, \%$. For continuous variables, $\mathrm{P}$ value was obtained by independent $\mathrm{t}$-test in order to show whether the mean is the same/different for boys compared to girls. For categorical variables, $\mathrm{P}$ value was obtained by Chi-square test.

*Classified according to Cole et al.(Cole \& Lobstein, 2012) and Bervoets et al.(Bervoets \& Massa, 2014)

$†$ Classified according to Hildebrand et al.(Hildebrand et al., 2016; Hildebrand et al., 2014) cut-off points for wrist. 
Table 2. Academic achievement measured by Woodcock-Johnson standardized test and school grades characteristics of the study sample.

\begin{tabular}{|c|c|c|c|c|}
\hline & All & Boys & Girls & \multirow[t]{2}{*}{$\mathrm{P}_{\mathrm{sex}}$} \\
\hline & Mean $\pm S D$ & Mean $\pm S D$ & Mean $\pm S D$ & \\
\hline \multicolumn{5}{|c|}{ Woodcock Muñoz Test (n=106; 61 boys): } \\
\hline Total achievement & $108.9 \pm 12.1$ & $108.2 \pm 11.6$ & $109.8 \pm 12.9$ & 0.493 \\
\hline Reading & $107.9 \pm 13.3$ & $107.7 \pm 12.1$ & $108.2 \pm 14.8$ & 0.852 \\
\hline Oral language & $90.2 \pm 13.7$ & $89.6 \pm 13.3$ & $91.1 \pm 14.2$ & 0.595 \\
\hline Writing & $113.5 \pm 13.0$ & $111.7 \pm 12.2$ & $115.9 \pm 13.7$ & 0.098 \\
\hline Written expression & $103.4 \pm 8.9$ & $102.5 \pm 9.0$ & $104.7 \pm 8.8$ & 0.210 \\
\hline Mathematics & $101.5 \pm 10.8$ & $101.7 \pm 11.7$ & $101.2 \pm 9.5$ & 0.833 \\
\hline Calculation skills & $102.9 \pm 11.9$ & $101.8 \pm 12.9$ & $104.4 \pm 10.3$ & 0.272 \\
\hline Science & $95.8 \pm 13.2$ & $96.3 \pm 12.0$ & $95.3 \pm 14.7$ & 0.702 \\
\hline \multicolumn{5}{|c|}{ School grades, scale from 1 to 5 ( $n=83 ; 49$ boys): } \\
\hline Grade point average & $3.7 \pm 0.9$ & $3.6 \pm 0.9$ & $3.8 \pm 0.9$ & 0.397 \\
\hline Language & $3.7 \pm 1.0$ & $3.6 \pm 0.9$ & $3.9 \pm 1.0$ & 0.243 \\
\hline Mathematics & $3.7 \pm 1.0$ & $3.7 \pm 1.0$ & $3.6 \pm 1.0$ & 0.659 \\
\hline Natural and Social Sciences & $3.7 \pm 1.0$ & $3.6 \pm 1.1$ & $3.8 \pm 0.9$ & 0.382 \\
\hline Foreign language & $3.6 \pm 1.1$ & $3.5 \pm 1.2$ & $3.9 \pm 1.1$ & 0.157 \\
\hline
\end{tabular}

$\mathrm{SD}=$ Standard deviation.

Data were presented as mean \pm standard deviation. $\mathrm{P}$ value was obtained by independent $\mathrm{t}$-test in order to test whether the mean differed between boys and girls. 
Table 3. Associations between physical fitness and academic achievement measured by Woodcock-Muñoz and school grades.

\begin{tabular}{|c|c|c|c|c|c|c|c|c|}
\hline & Model & 20m SRT (laps) & $\begin{array}{l}\text { Handgrip } \\
\text { strength (kg) }\end{array}$ & $\begin{array}{l}\text { Standing long } \\
\text { jump }(\mathrm{cm})\end{array}$ & $\begin{array}{l}\text { 4x10m SRT } \\
(\mathrm{sec}) \dagger\end{array}$ & $\begin{array}{l}\text { Treadmill test } \\
\text { (VO } 2 \text { peak) }\end{array}$ & $\begin{array}{l}\text { 1-RM bench } \\
\text { press }\end{array}$ & 1-RM leg press \\
\hline \multicolumn{9}{|l|}{ Woodcock-Muñoz: } \\
\hline \multirow[t]{2}{*}{ Total achievement } & 1 & $\begin{array}{c}0.197^{*} \\
(0.012,0.382)\end{array}$ & $\begin{array}{c}0.137 \\
(-0.072,0.347)\end{array}$ & $\begin{array}{c}0.210^{*} \\
(0.034,0.385)\end{array}$ & $\begin{array}{c}0.223^{*} \\
(0.041,0.405)\end{array}$ & $\begin{array}{c}0.075 \\
(-0.097,0.248)\end{array}$ & $\begin{array}{c}0.074 \\
(-0.116,0.264)\end{array}$ & $\begin{array}{c}0.213^{*} \\
(0.032,0.394)\end{array}$ \\
\hline & 2 & $\begin{array}{c}0.106 \\
(-0.163,0.374)\end{array}$ & $\begin{array}{c}0.119 \\
(-0.103,0.341)\end{array}$ & $\begin{array}{c}0.157 \\
(-0.052,0.365)\end{array}$ & $\begin{array}{c}0.178 \\
(-0.076,0.431)\end{array}$ & $\begin{array}{c}-0.049 \\
(-0.292,0.194)\end{array}$ & $\begin{array}{c}0.033 \\
(-0.180,0.246)\end{array}$ & $\begin{array}{c}0.299 * * \\
(0.085,0.513)\end{array}$ \\
\hline \multirow[t]{2}{*}{ Reading } & 1 & $\begin{array}{c}0.090 \\
(-0.100,0.280)\end{array}$ & $\begin{array}{c}0.042 \\
(-0.172,0.255)\end{array}$ & $\begin{array}{c}0.166 \\
(-0.013,0.346)\end{array}$ & $\begin{array}{c}0.115 \\
(-0.073,0.303)\end{array}$ & $\begin{array}{c}0.019 \\
(-0.156,0.194)\end{array}$ & $\begin{array}{c}0.080 \\
(-0.094,0.255)\end{array}$ & $\begin{array}{c}0.159 \\
(-0.009,0.326)\end{array}$ \\
\hline & 2 & $\begin{array}{c}0.042 \\
(-0.236,0.320)\end{array}$ & $\begin{array}{c}0.024 \\
(-0.206,0.253)\end{array}$ & $\begin{array}{c}0.172 \\
(-0.042,0.387)\end{array}$ & $\begin{array}{c}0.110 \\
(-0.152,0.372)\end{array}$ & $\begin{array}{c}-0.047 \\
(-0.298,0.203)\end{array}$ & $\begin{array}{c}0.131 \\
(-0.065,0.328)\end{array}$ & $\begin{array}{c}0.288 * * \\
(-0.089,0.487)\end{array}$ \\
\hline \multirow[t]{2}{*}{ Oral language } & 1 & $\begin{array}{c}0.064 \\
(-0.146,0.275)\end{array}$ & $\begin{array}{c}0.250 * \\
(0.019,0.481)\end{array}$ & $\begin{array}{c}0.121 \\
(-0.080,0.321)\end{array}$ & $\begin{array}{c}0.006 \\
(-0.203,0.215)\end{array}$ & $\begin{array}{c}0.045 \\
(-0.148,0.238)\end{array}$ & $\begin{array}{c}0.035 \\
(-0.173,0.243)\end{array}$ & $\begin{array}{c}-0.035 \\
(-0.238,0.168)\end{array}$ \\
\hline & 2 & $\begin{array}{c}0.090 \\
(-0.218,0.398)\end{array}$ & $\begin{array}{c}0.288 * \\
(0.040,0.535)\end{array}$ & $\begin{array}{c}0.120 \\
(-0.119,0.359)\end{array}$ & $\begin{array}{c}0.078 \\
(-0.369,0.213)\end{array}$ & $\begin{array}{c}0.024 \\
(-0.254,0.303)\end{array}$ & $\begin{array}{c}0.007 \\
(-0.164,0.303)\end{array}$ & $\begin{array}{c}0.012 \\
(-0.232,0.255)\end{array}$ \\
\hline \multirow[t]{2}{*}{ Writing } & 1 & $\begin{array}{c}0.281 * * \\
(0.086,0.477)\end{array}$ & $\begin{array}{c}0.125 \\
(-0.102,0.351)\end{array}$ & $\begin{array}{c}0.193 * \\
(0.002,0.384)\end{array}$ & $\begin{array}{c}0.325 * * \\
(0.134,0.517)\end{array}$ & $\begin{array}{c}0.074 \\
(-0.112,0.260)\end{array}$ & $\begin{array}{c}0.029 \\
(-0.192,0.250)\end{array}$ & $\begin{array}{c}0.193 \\
(-0.020,0.406)\end{array}$ \\
\hline & 2 & $\begin{array}{c}0.132 \\
(-0.149,0.414)\end{array}$ & $\begin{array}{c}0.096 \\
(-0.140,0.332)\end{array}$ & $\begin{array}{c}0.073 \\
(-0.150,0.296)\end{array}$ & $\begin{array}{c}0.263 \\
(-0.003,0.529)\end{array}$ & $\begin{array}{c}-0.159 \\
(-0.413,0.094)\end{array}$ & $\begin{array}{c}-0.112 \\
(-0.350,0.127)\end{array}$ & $\begin{array}{c}0.201 \\
(-0.047,0.448)\end{array}$ \\
\hline \multirow[t]{2}{*}{$\begin{array}{l}\text { Written } \\
\text { expression }\end{array}$} & 1 & $\begin{array}{c}0.365 * * \\
(0.171,0.560)\end{array}$ & $\begin{array}{c}0.164 \\
(-0.065,0.394)\end{array}$ & $\begin{array}{c}0.212 * \\
(0.019,0.406)\end{array}$ & $\begin{array}{c}0.393 * * \\
(0.203,0.584)\end{array}$ & $\begin{array}{c}0.199 * \\
(0.013,0.385)\end{array}$ & $\begin{array}{c}0.093 \\
(-0.127,0.314)\end{array}$ & $\begin{array}{c}0.218^{*} \\
(0.008,0.429)\end{array}$ \\
\hline & 2 & $\begin{array}{c}0.206 \\
(-0.072,0.485)\end{array}$ & $\begin{array}{c}0.126 \\
(-0.107,0.360)\end{array}$ & $\begin{array}{c}0.041 \\
(-0.180,0.263)\end{array}$ & $\begin{array}{c}0.286 * \\
(0.023,0.549)\end{array}$ & $\begin{array}{c}0.020 \\
(-0.234,0.274)\end{array}$ & $\begin{array}{c}0.078 \\
(-0.308,0.151)\end{array}$ & $\begin{array}{c}0.242 \\
(0.008,0.475)\end{array}$ \\
\hline \multirow[t]{2}{*}{ Mathematics } & 1 & $\begin{array}{c}0.170 \\
(-0.022,0.363)\end{array}$ & $\begin{array}{c}0.198 \\
(-0.017,0.414)\end{array}$ & $\begin{array}{c}0.193 * \\
(0.011,0.376)\end{array}$ & $\begin{array}{c}0.167 \\
(-0.024,0.358)\end{array}$ & $\begin{array}{c}0.087 \\
(-0.091,0.265)\end{array}$ & $\begin{array}{c}0.082 \\
(-0.126,0.290)\end{array}$ & $\begin{array}{c}0.251 * * \\
(0.055,0.447)\end{array}$ \\
\hline & 2 & $\begin{array}{c}0.133 \\
(-0.148,0.414)\end{array}$ & $\begin{array}{c}0.183 \\
(-0.046,0.412)\end{array}$ & $\begin{array}{c}0.155 \\
(-0.062,0.373)\end{array}$ & $\begin{array}{c}0.111 \\
(-0.154,0.376)\end{array}$ & $\begin{array}{c}0.036 \\
(0.218,0.291)\end{array}$ & $\begin{array}{c}0.039 \\
(-0.195,0.273)\end{array}$ & $\begin{array}{c}0.316 * * \\
(0.083,0.549)\end{array}$ \\
\hline \multirow[t]{2}{*}{ Calculation skills } & 1 & $\begin{array}{c}0.054 \\
(-0.141,0.248)\end{array}$ & $\begin{array}{c}0.172 \\
(-0.043,0.387)\end{array}$ & $\begin{array}{c}0.100 \\
(-0.085,0.285)\end{array}$ & $\begin{array}{c}0.169 \\
(-0.022,0.359)\end{array}$ & $\begin{array}{c}0.056 \\
(-0.122,0.234)\end{array}$ & $\begin{array}{c}0.061 \\
(-0.153,0.274)\end{array}$ & $\begin{array}{c}0.306 * * \\
(0.109,0.504)\end{array}$ \\
\hline & 2 & $\begin{array}{c}-0.070 \\
(-0.349,0.209)\end{array}$ & $\begin{array}{c}0.168 \\
(-0.064,0.400)\end{array}$ & $\begin{array}{c}0.107 \\
(-0.133,0.328)\end{array}$ & $\begin{array}{c}0.265^{*} \\
(0.002,0.529)\end{array}$ & $\begin{array}{c}0.046 \\
(-0.209,0.315)\end{array}$ & $\begin{array}{c}0.045 \\
(-0.196,0.286)\end{array}$ & $\begin{array}{c}0.383 * * \\
(0.147,0.618)\end{array}$ \\
\hline Science & 1 & $\begin{array}{c}-0.106 \\
(-0.303,0.092)\end{array}$ & $\begin{array}{c}0.114 \\
(-0.108,0.335)\end{array}$ & $\begin{array}{c}0.053 \\
(-0.136,0.243)\end{array}$ & $\begin{array}{c}0.074 \\
(-0.273,0.123)\end{array}$ & $\begin{array}{c}-0.009 \\
(-0.191,0.172)\end{array}$ & $\begin{array}{c}0.046 \\
(-0.162,0.254)\end{array}$ & $\begin{array}{c}0.135 \\
(-0.066,0.336)\end{array}$ \\
\hline
\end{tabular}




\begin{tabular}{|c|c|c|c|c|c|c|c|c|}
\hline & 2 & $\begin{array}{c}-0.117 \\
(-0.406,0.172)\end{array}$ & $\begin{array}{c}0.158 \\
(-0.078,0.394)\end{array}$ & $\begin{array}{c}0.145 \\
(-0.078,0.369)\end{array}$ & $\begin{array}{c}-0.013 \\
(-0.286,0.260)\end{array}$ & $\begin{array}{c}0.053 \\
(-0.209,0.315)\end{array}$ & $\begin{array}{c}0.095 \\
(-0.138,0.328)\end{array}$ & $\begin{array}{c}0.178 \\
(-0.062,0.419)\end{array}$ \\
\hline \multicolumn{9}{|l|}{ School grades: } \\
\hline $\begin{array}{l}\text { Grade point } \\
\text { average }\end{array}$ & 1 & $\begin{array}{c}0.129 \\
(-0.097,0.354) \\
0.263 \\
(-0.062,0.588)\end{array}$ & $\begin{array}{c}0.280 * * \\
(0.058,0.503) \\
0.273 * \\
(0.028,0.518)\end{array}$ & $\begin{array}{c}0.065 \\
(-0.151,0.281) \\
0.017 \\
(-0.232,0.266)\end{array}$ & $\begin{array}{c}0.013 \\
(-0.208,0.235) \\
-0.115 \\
(-0.431,0.202)\end{array}$ & $\begin{array}{c}-0.010 \\
(-0.206,0.186) \\
-0.003 \\
(-0.284,0.277)\end{array}$ & $\begin{array}{c}0.038 \\
(-0.198,0.274) \\
-0.065 \\
(-0.327,0.198)\end{array}$ & $\begin{array}{c}0.146 \\
(-0.113,0.406) \\
0.031 \\
(-0.292,0.353)\end{array}$ \\
\hline Language & 1 & $\begin{array}{c}0.100 \\
(0.129,0.329)\end{array}$ & $\begin{array}{c}0.214 \\
(-0.015,0.443)\end{array}$ & $\begin{array}{c}0.050 \\
(-0.169,0.268)\end{array}$ & $\begin{array}{c}0.047 \\
(-0.177,0.271)\end{array}$ & $\begin{array}{c}-0.013 \\
(-0.211,0.185)\end{array}$ & $\begin{array}{c}0.073 \\
(-0.162,0.309)\end{array}$ & $\begin{array}{c}0.177 \\
(-0.082,0.436)\end{array}$ \\
\hline & 2 & $\begin{array}{c}0.170 \\
(-0.161,0.500)\end{array}$ & $\begin{array}{c}0.193 \\
(-0.060,0.446)\end{array}$ & $\begin{array}{c}0.015 \\
(-0.237,0.268)\end{array}$ & $\begin{array}{c}0.000 \\
(-0.322,0.322)\end{array}$ & $\begin{array}{c}-0.008 \\
(-0.290,0.275)\end{array}$ & $\begin{array}{c}-0.002 \\
(-0.267,0.263)\end{array}$ & $\begin{array}{c}0.098 \\
(-0.338,0.321)\end{array}$ \\
\hline Mathematics & 1 & $\begin{array}{c}0.074 \\
(-0.155,0.303)\end{array}$ & $\begin{array}{c}0.272 \\
(0.046,0.498)\end{array}$ & $\begin{array}{c}0.007 \\
(-0.212,0.227)\end{array}$ & $\begin{array}{c}0.054 \\
(-0.278,0.170)\end{array}$ & $\begin{array}{c}-0.076 \\
(-0.273,0.121)\end{array}$ & $\begin{array}{c}0.031 \\
(-0.212,0.273)\end{array}$ & $\begin{array}{c}0.148 \\
(-0.119,0.414)\end{array}$ \\
\hline & 2 & $\begin{array}{c}0.268 \\
(-0.060,0.595)\end{array}$ & $\begin{array}{c}0.247 \\
(-0.003,0.496)\end{array}$ & $\begin{array}{c}-0.019 \\
(-0.271,0.232)\end{array}$ & $\begin{array}{c}-0.158 \\
(-0.477,0.161)\end{array}$ & $\begin{array}{c}-0.034 \\
(-0.317,0.248)\end{array}$ & $\begin{array}{c}-0.067 \\
(-0.335,0.200)\end{array}$ & $\begin{array}{c}-0.008 \\
(-0.338,0.321)\end{array}$ \\
\hline $\begin{array}{l}\text { Natural and } \\
\text { Social Sciences }\end{array}$ & 1 & $\begin{array}{c}0.184 \\
(-0.0430 .411)\end{array}$ & $\begin{array}{c}0.294 * * \\
(0.069,0.520)\end{array}$ & $\begin{array}{c}0.123 \\
(-0.095,0.341)\end{array}$ & $\begin{array}{c}0.045 \\
(-0.180,0.270)\end{array}$ & $\begin{array}{c}0.061 \\
(-0.138,0.259)\end{array}$ & $\begin{array}{c}0.004 \\
(-0.233,0.240)\end{array}$ & $\begin{array}{c}0.086 \\
(-0.175,0.347)\end{array}$ \\
\hline & 2 & $\begin{array}{c}0.293 \\
(-0.035,0.621)\end{array}$ & $\begin{array}{c}0.320 * * \\
(0.073,0.566)\end{array}$ & $\begin{array}{c}0.052 \\
(-0.200,0.304)\end{array}$ & $\begin{array}{c}-0.157 \\
(-0.477,0.163)\end{array}$ & $\begin{array}{c}0.032 \\
(-0.252,0.317)\end{array}$ & $\begin{array}{c}-0.108 \\
(-0.370,0.155)\end{array}$ & $\begin{array}{c}0.003 \\
(-0.321,0.326)\end{array}$ \\
\hline Foreign Language & 1 & $\begin{array}{c}0.092 \\
(-0.142,0.326)\end{array}$ & $\begin{array}{c}0.326 * * \\
(0.098,0.553)\end{array}$ & $\begin{array}{c}0.168 \\
(-0.052,0.389)\end{array}$ & $\begin{array}{c}0.047 \\
(-0.182,0.276)\end{array}$ & $\begin{array}{c}-0.021 \\
(-0.223,0.182)\end{array}$ & $\begin{array}{c}-0.052 \\
(-0.283,0.180)\end{array}$ & $\begin{array}{c}0.172 \\
(-0.081,0.425)\end{array}$ \\
\hline & 2 & $\begin{array}{c}0.171 \\
(-0.165,0.508)\end{array}$ & $\begin{array}{c}0.314 * * \\
(0.063,0.565)\end{array}$ & $\begin{array}{c}0.180 \\
(-0.074,0.433) \\
\end{array}$ & $\begin{array}{c}0.026 \\
(-0.302,0.354)\end{array}$ & $\begin{array}{c}0.014 \\
(-0.273,0.302)\end{array}$ & $\begin{array}{c}-0.121 \\
(-0.380,0.137)\end{array}$ & $\begin{array}{c}0.085 \\
(-0.233,0.404) \\
\end{array}$ \\
\hline
\end{tabular}

Data are standardized regression coefficients ( $95 \%$ confidence interval) adjusted for age, sex and maternal education in model 1 , and further for body mass index, and cardiorespiratory fitness (except for cardiorespiratory fitness, which was adjusted for speed agility fitness in Model 2).

$* \mathrm{p} \leq 0.05$

$* * \mathrm{p} \leq 0.01$

$\dagger$ Values were multiplied by -1 before analyses so that higher values indicate better performance. 
Table 4. Associations between physical activity and academic achievement measured by Woodcock-Muñoz and school grades.

\begin{tabular}{|c|c|c|c|c|c|c|c|c|}
\hline & Model & Light PA & Moderate PA & Vigorous PA & MVPA & $\begin{array}{l}\text { 1-min } \\
\text { bouts MVPA }\end{array}$ & $\begin{array}{l}\text { 5-min bouts } \\
\text { MVPA }\end{array}$ & $\begin{array}{l}\text { 10-min bouts } \\
\text { MVPA }\end{array}$ \\
\hline \multicolumn{9}{|l|}{ Woodcock-Muñoz: } \\
\hline \multirow[t]{2}{*}{ Total achievement } & 1 & $\begin{array}{c}0.096 \\
(-0.077,0.269)\end{array}$ & $\begin{array}{c}0.044 \\
(-0.151,0.240)\end{array}$ & $\begin{array}{c}-0.003 \\
(-0.201,0.195)\end{array}$ & $\begin{array}{c}0.037 \\
(-0.161,0.236)\end{array}$ & $\begin{array}{c}-0.003 \\
(-0.208,0.201)\end{array}$ & $\begin{array}{c}0.015 \\
(-0.172,0.202)\end{array}$ & $\begin{array}{c}0.028 \\
(-0.154,0.209)\end{array}$ \\
\hline & 2 & $\begin{array}{c}0.097 \\
(-0.076,0.271)\end{array}$ & $\begin{array}{c}-0.013 \\
(-0.221,0.195)\end{array}$ & $\begin{array}{c}-0.108 \\
(-0.324,0.108)\end{array}$ & $\begin{array}{c}-0.034 \\
(-0.249,0.180)\end{array}$ & $\begin{array}{c}-0.077 \\
(-0.292,0.139)\end{array}$ & $\begin{array}{c}-0.031 \\
(-0.221,0.160)\end{array}$ & $\begin{array}{c}-0.008 \\
(-0.191,0.175)\end{array}$ \\
\hline \multirow[t]{2}{*}{ Reading } & 1 & $\begin{array}{c}0.085 \\
(-0.091,0.262)\end{array}$ & $\begin{array}{c}-0.001 \\
(-0.200,0.198)\end{array}$ & $\begin{array}{c}-0.026 \\
(-0.227,0.176)\end{array}$ & $\begin{array}{c}-0.006 \\
(-0.209,0.196)\end{array}$ & $\begin{array}{c}-0.030 \\
(-0.238,0.178)\end{array}$ & $\begin{array}{c}-0.044 \\
(-0.234,0.147)\end{array}$ & $\begin{array}{c}-0.049 \\
(-0.234,0.135)\end{array}$ \\
\hline & 2 & $\begin{array}{c}0.087 \\
(-0.093,0.267)\end{array}$ & $\begin{array}{c}-0.032 \\
(-0.248,0.183)\end{array}$ & $\begin{array}{c}-0.083 \\
(-0.308,0.141)\end{array}$ & $\begin{array}{c}-0.046 \\
(-0.268,0.176)\end{array}$ & $\begin{array}{c}-0.070 \\
(-0.294,0.153)\end{array}$ & $\begin{array}{c}-0.007 \\
(-0.267,0.127)\end{array}$ & $\begin{array}{c}-0.007 \\
(-0.258,0.119)\end{array}$ \\
\hline \multirow[t]{2}{*}{ Oral language } & 1 & $\begin{array}{c}0.134 \\
(-0.059,0.327)\end{array}$ & $\begin{array}{c}0.115 \\
(-0.103,0.333)\end{array}$ & $\begin{array}{c}0.122 \\
(-0.099,0.343)\end{array}$ & $\begin{array}{c}0.125 \\
(-0.097,0.346)\end{array}$ & $\begin{array}{c}0.147 \\
(-0.081,0.374)\end{array}$ & $\begin{array}{c}0.075 \\
(-0.135,0.284)\end{array}$ & $\begin{array}{c}0.087 \\
(-0.116,0.290)\end{array}$ \\
\hline & 2 & $\begin{array}{c}0.129 \\
(-0.069,0.327)\end{array}$ & $\begin{array}{c}0.093 \\
(-0.144,0.331)\end{array}$ & $\begin{array}{c}0.102 \\
(-0.146,0.349)\end{array}$ & $\begin{array}{c}0.103 \\
(-0.141,0.347)\end{array}$ & $\begin{array}{c}0.128 \\
(-0.117,0.374)\end{array}$ & $\begin{array}{c}0.057 \\
(-0.161,0.275)\end{array}$ & $\begin{array}{c}0.078 \\
(-0.131,0.286)\end{array}$ \\
\hline \multirow[t]{2}{*}{ Writing } & 1 & $\begin{array}{c}0.085 \\
(-0.100,0.270)\end{array}$ & $\begin{array}{c}0.027 \\
(-0.182,0.235)\end{array}$ & $\begin{array}{c}0.005 \\
(-0.207,0.216)\end{array}$ & $\begin{array}{c}0.024 \\
(-0.188,0.236)\end{array}$ & $\begin{array}{c}-0.014 \\
(-0.232,0.204)\end{array}$ & $\begin{array}{c}-0.015 \\
(-0.215,0.185)\end{array}$ & $\begin{array}{c}0.068 \\
(-0.126,0.261)\end{array}$ \\
\hline & 2 & $\begin{array}{c}0.085 \\
(-0.099,0.268)\end{array}$ & $\begin{array}{c}-0.056 \\
(-0.275,0.163)\end{array}$ & $\begin{array}{c}-0.133 \\
(-0.360,0.094)\end{array}$ & $\begin{array}{c}-0.077 \\
(-0.302,0.148)\end{array}$ & $\begin{array}{c}-0.114 \\
(-0.341,0.113)\end{array}$ & $\begin{array}{c}-0.078 \\
(-0.279,0.122)\end{array}$ & $\begin{array}{c}0.021 \\
(-0.171,0.214)\end{array}$ \\
\hline \multirow[t]{2}{*}{ Written expression } & 1 & $\begin{array}{c}0.091 \\
(-0.096,0.278)\end{array}$ & $\begin{array}{c}0.037 \\
(-0.174,0.248)\end{array}$ & $\begin{array}{c}0.055 \\
(-0.158,0.269)\end{array}$ & $\begin{array}{c}0.044 \\
(-0.171,0.258)\end{array}$ & $\begin{array}{c}-0.034 \\
(-0.254,0.187)\end{array}$ & $\begin{array}{c}-0.073 \\
(-0.275,0.128)\end{array}$ & $\begin{array}{c}0.092 \\
(-0.104,0.287)\end{array}$ \\
\hline & 2 & $\begin{array}{c}0.079 \\
(-0.100,0.258)\end{array}$ & $\begin{array}{c}-0.100 \\
(-0.313,0.113)\end{array}$ & $\begin{array}{c}-0.138 \\
(-0.359,0.083)\end{array}$ & $\begin{array}{c}-0.117 \\
(-0.336,0.102)\end{array}$ & $\begin{array}{c}-0.193 \\
(-0.411,0.026)\end{array}$ & $\begin{array}{c}-0.173 \\
(-0.366,0.020)\end{array}$ & $\begin{array}{c}0.029 \\
(-0.159,0.216)\end{array}$ \\
\hline \multirow[t]{2}{*}{ Mathematics } & 1 & $\begin{array}{c}0.072 \\
(-0.108,0.252)\end{array}$ & $\begin{array}{c}0.094 \\
(-0.107,0.296)\end{array}$ & $\begin{array}{c}0.015 \\
(-0.190,0.220)\end{array}$ & $\begin{array}{c}0.084 \\
(-0.122,0.289)\end{array}$ & $\begin{array}{c}0.058 \\
(-0.154,0.269)\end{array}$ & $\begin{array}{c}0.099 \\
(-0.094,0.292)\end{array}$ & $\begin{array}{c}0.072 \\
(-0.116,0.259)\end{array}$ \\
\hline & 2 & $\begin{array}{c}0.076 \\
(-0.105,0.257)\end{array}$ & $\begin{array}{c}0.057 \\
(-0.159,0.273)\end{array}$ & $\begin{array}{c}-0.073 \\
(-0.299,0.152)\end{array}$ & $\begin{array}{c}0.034 \\
(-0.189,0.257)\end{array}$ & $\begin{array}{c}0.004 \\
(-0.221,0.229)\end{array}$ & $\begin{array}{c}0.064 \\
(-0.134,0.262)\end{array}$ & $\begin{array}{c}0.039 \\
(-0.151,0.229)\end{array}$ \\
\hline \multirow[t]{2}{*}{ Calculation skills } & 1 & $\begin{array}{c}0.086 \\
(-0.093,0.265)\end{array}$ & $\begin{array}{c}0.035 \\
(-0.167,0.236)\end{array}$ & $\begin{array}{c}-0.036 \\
(-0.240,0.169)\end{array}$ & $\begin{array}{c}0.022 \\
(-0.183,0.227)\end{array}$ & $\begin{array}{c}-0.016 \\
(-0.227,0.196)\end{array}$ & $\begin{array}{c}0.034 \\
(-0.159,0.227)\end{array}$ & $\begin{array}{c}0.048 \\
(-0.140,0.235)\end{array}$ \\
\hline & 2 & $\begin{array}{c}0.096 \\
(-0.087,0.279)\end{array}$ & $\begin{array}{c}0.034 \\
(-0.185,0.253)\end{array}$ & $\begin{array}{c}-0.068 \\
(-0.296,0.160)\end{array}$ & $\begin{array}{c}0.016 \\
(-0.210,0.241)\end{array}$ & $\begin{array}{c}-0.029 \\
(-0.257,0.198)\end{array}$ & $\begin{array}{c}0.026 \\
(-0.175,0.227)\end{array}$ & $\begin{array}{c}0.036 \\
(-0.156,0.228)\end{array}$ \\
\hline Science & 1 & $\begin{array}{c}-0.007 \\
(-0.193,0.178)\end{array}$ & $\begin{array}{c}0.006 \\
(-0.203,0.214)\end{array}$ & $\begin{array}{c}-0.042 \\
(-0.253,0.169)\end{array}$ & $\begin{array}{c}-0.004 \\
(-0.216,0.207)\end{array}$ & $\begin{array}{c}0.032 \\
(-0.186,0.250)\end{array}$ & $\begin{array}{c}0.038 \\
(-0.161,0.238)\end{array}$ & $\begin{array}{c}0.025 \\
(-0.169,0.218)\end{array}$ \\
\hline
\end{tabular}




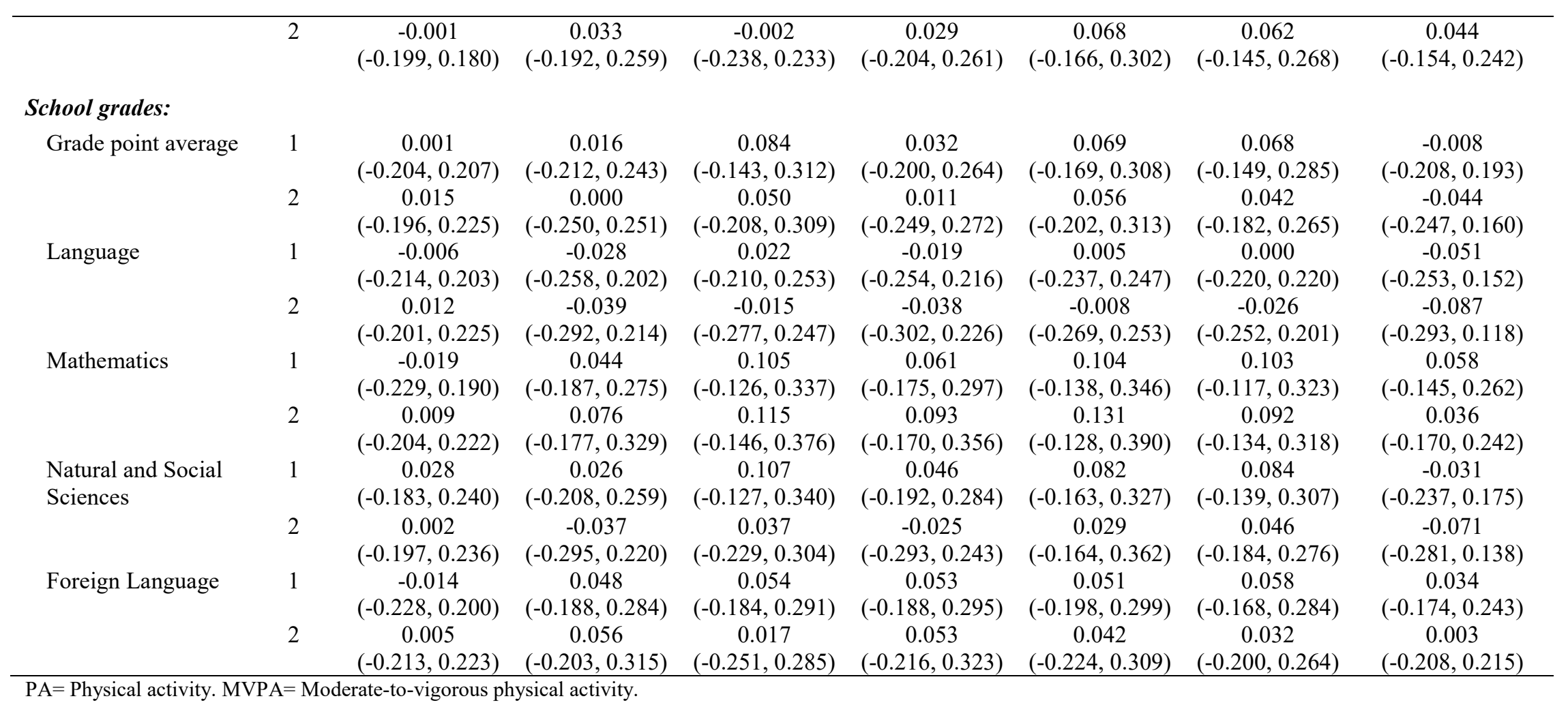

Data are standardized regression coefficients ( $95 \%$ confidence interval) adjusted for age, sex and maternal education in model 1 , and further for body mass index, and cardiorespiratory fitness (except for cardiorespiratory fitness, which was adjusted for speed agility fitness in Model 2).

Physical activity data was classified according to the Hildebrand et al. (Hildebrand, Hansen, van Hees, \& Ekelund, 2016; Hildebrand, VT, Hansen, \& Ekelund, 2014) cut-off points. 
Supplemental Digital content 1. Detailed information on the data collection and processing criteria of the physical activity measurement.

The raw data collected at a sampling frequency of $100 \mathrm{~Hz}$ were processed in $\mathrm{R}$ (v. 3.1.2, https:// www.cran.r-project.org/) using the GGIR package (v. 1.5-12, https://cran.rproject.org/web/packages/GGIR/) ${ }^{1}$ and in the ActiLife software (v.6.13.3, ActiGraph TM, Pensacola, FL). To process the data in the GGIR package 1) we auto-calibrated of the signal according to the local gravity $\left.{ }^{2} ; 2\right)$ we derived the mean of the Euclidian Norm Minus One $\mathrm{G}\left(\mathrm{ENMO}, 1 \mathrm{G}=1\right.$ gravitational acceleration $\left.\sim 9.8 \mathrm{~m} / \mathrm{s}^{2}\right)$ with negative values rounded to zero; 3 ) we imported the ActiGraph's activity counts over 5s epochs derived from the ActiLife software using the default filter; 4) we calculated the nonwear time using the approach described by Van Hees et al. ${ }^{3}$ Briefly, 15-min blocks were classified as non-wear time if the standard deviation of 2 out of the 3 axes was lower than $13 \mathrm{mg}$ during the surrounding 60-min moving window; 5) we identified the clipping scores, i.e., atypical high accelerations related to malfunctioning of the accelerometers; 6) we detected imputations of the non-wear and clipped time by means of the rest of the days during the same time interval as the detected window ${ }^{4}$. If no data were collected for the certain window for the rest of the days, then, non-wear time was replaced by 0 ; and 7) we identified of the sleeping hours based on an automatized algorithm based on the anteroposterior angle estimated from the accelerometer ${ }^{5}$ guided by the sleep onset and waking-up times reported by the participants.

The inclusion criterion was $\geq 600 \mathrm{~min} /$ day of waking hours and $\geq 240 \mathrm{~min} /$ day of sleeping hours for a valid day, and a minimum of 4 days ( 3 weekdays and 1 weekend day) to be included in the analyses. The compliance with wearing the accelerometer was high with $98 \%$ of sample wearing it $\geq 6$ days. 


\section{References}

1. van Hees VT, Gorzelniak L, Dean Leon EC, et al. Separating movement and gravity components in an acceleration signal and implications for the assessment of human daily physical activity. PloS one 2013; 8(4): e61691.

2. van Hees VT, Fang Z, Langford J, et al. Autocalibration of accelerometer data for free-living physical activity assessment using local gravity and temperature: an evaluation on four continents. Journal of Applied Physiology (Bethesda, Md : 1985) 2014; 117(7): 738-44.

3. van Hees VT, Renstrom F, Wright A, et al. Estimation of daily energy expenditure in pregnant and non-pregnant women using a wrist-worn tri-axial accelerometer. PloS one 2011; 6(7): e22922.

4. Staudenmayer J, Zhu W, Catellier DJ. Statistical considerations in the analysis of accelerometry-based activity monitor data. Medicine and Science in Sports and Exercise 2012; 44(1 Suppl 1): S61-7.

5. Van Hees VT, Sabia S, Anderson KN, Denton SJ, Oliver J, Catt M, Abell JG, Kivimäki M, Trenell MI, Singh-Manoux A. A novel, open access method to assess sleep duration using a wrist-worn accelerometer. PloS One 2015; 10(11):e0142533. 


\section{Supplemental Digital Content 2}

Table S1. Academic achievement components of the Woodcock Johnson standardized test.

\section{Component Definition}

Total achievement

Reading

Oral language

Writing

Written expression

Mathematics

Calculation skills

Science
Overall measure of the academic performance based on reading, mathematics, and writing.

Broad measure of the reading performance that includes word identification, reading speed, and comprehension.

Measure of the linguistic competency, listening ability, and oral comprehension.

Broad measure of the written language performance, which includes spelling, quality of written sentences, and speed of writing.

Combined measure between writing speed and the quality of the sentence (meaningful, coherence, etc.).

Broad measure of mathematics performance which includes calculation skills, problem solving, and the ability to subtract, sum, multiply, or divide quickly.

Combined measured of mathematics based on doing simple calculations quickly and the ability to perform mathematical computations.

Measure of the knowledge in sciences, history, geography, government, economics, art, music and literature. 


\section{Supplemental Digital Content 3}

Table S2. Bivariate correlations between physical fitness and physical activity.

\begin{tabular}{|c|c|c|c|c|c|c|c|c|c|c|c|c|c|c|}
\hline & $\begin{array}{l}\text { 20m SRT } \\
\text { (laps) }\end{array}$ & $\begin{array}{l}\text { Handgrip } \\
\text { strength } \\
(\mathrm{kg})\end{array}$ & $\begin{array}{l}\text { Standing } \\
\text { long jump } \\
\text { (cm) }\end{array}$ & $\begin{array}{l}4 \times 10 \mathrm{~m} \\
\text { SRT } \\
(\mathrm{sec}) \dagger\end{array}$ & $\begin{array}{l}\text { Treadmill } \\
\text { test } \\
\text { (VO2peak) }\end{array}$ & $\begin{array}{l}1-\mathrm{RM} \\
\text { bench } \\
\text { press }\end{array}$ & $\begin{array}{l}\text { 1-RM } \\
\text { leg press }\end{array}$ & $\begin{array}{l}\text { Light } \\
\text { PA }\end{array}$ & $\begin{array}{l}\text { Moderate } \\
\text { PA }\end{array}$ & $\begin{array}{l}\text { Vigorous } \\
\text { PA }\end{array}$ & MVPA & $\begin{array}{l}\text { 1-min } \\
\text { bouts } \\
\text { MVPA }\end{array}$ & $\begin{array}{l}\text { 5-min } \\
\text { bouts } \\
\text { MVPA }\end{array}$ & $\begin{array}{l}\text { 10-min } \\
\text { bouts } \\
\text { MVPA }\end{array}$ \\
\hline 20m SRT (laps) & 1 & $0.310^{* *}$ & $0.601 * *$ & $0.740 * *$ & $0.656 * *$ & $0.449 * *$ & 0.167 & -0.031 & $0.243 *$ & $0.335 * *$ & $0.274 * *$ & $0.292 * *$ & 0.231* & 0.158 \\
\hline Handgrip strength (kg) & & 1 & $0.392 * *$ & $0.361 * *$ & 0.090 & $0.547 * *$ & $0.465 * *$ & 0.153 & 0.021 & -0.033 & 0.010 & 0.022 & 0.080 & 0.049 \\
\hline Standing long jump (cm) & & & 1 & $0.730 * *$ & $0.489 * *$ & $0.569 * *$ & $0.375^{* *}$ & 0.130 & 0.054 & 0.146 & 0.077 & 0.097 & 0.118 & 0.061 \\
\hline 4x10m SRT (sec) $\dagger$ & & & & 1 & $0.525^{* *}$ & $0.517^{* *}$ & $0.291 * *$ & -0.004 & 0.079 & 0.107 & 0.088 & 0.118 & 0.054 & 0.009 \\
\hline Treadmill test ( $\mathrm{VO}_{2}$ peak) & & & & & 1 & $0.292 * *$ & -0.089 & 0.139 & $0.353^{* * *}$ & $0.254 * *$ & $0.347^{* *}$ & $0.287 * *$ & $0.246 *$ & 0.181 \\
\hline 1-RM bench press & & & & & & 1 & $0.467 * *$ & 0.011 & 0.041 & 0.122 & 0.061 & 0.097 & 0.091 & 0.014 \\
\hline 1-RM leg press & & & & & & & 1 & -0.131 & -0.192 & -0.067 & -0.174 & -0.082 & -0.020 & -0.033 \\
\hline Light PA & & & & & & & & 1 & $0.342 * *$ & 0.037 & $0.291 * *$ & 0.062 & 0.055 & 0.006 \\
\hline Moderate PA & & & & & & & & & 1 & $0.752^{* *}$ & $0.990 * *$ & $0.870^{* *}$ & $0.747^{* *}$ & $0.620^{* *}$ \\
\hline Vigorous PA & & & & & & & & & & 1 & $0.839 * *$ & $0.821 * *$ & $0.762 * *$ & $0.673 * *$ \\
\hline MVPA & & & & & & & & & & & 1 & $0.897 * *$ & $0.783 * *$ & $0.658^{* *}$ \\
\hline 1-min bouts MVPA & & & & & & & & & & & & 1 & $0.750 * *$ & $0.530^{* *}$ \\
\hline 5-min bouts MVPA & & & & & & & & & & & & & 1 & $0.650^{* *}$ \\
\hline 10-min bouts MVPA & & & & & & & & & & & & & & 1 \\
\hline
\end{tabular}

$\mathrm{RM}=$ Repetition maximum. $\mathrm{VO}_{2} \mathrm{max}=$ maximum oxygen volume. $\mathrm{PA}=$ physical activity. $\mathrm{MVPA}=$ moderate-to-vigorous physical activity.

$* \mathrm{p} \leq 0.05$

$* * \mathrm{p} \leq 0.01$

$\dagger$ Values were multiplied by -1 before analyses so that higher values indicate better performance 